\title{
Investigating the potential for using gamification to empower knowledge workers
}

Agnessa Spanellis

Department of Business Management, Heriot Watt University, Edinburgh, UK, The Avenue, Currie EH14 4AS, +44 (0) 7563244 742, a.spanellis@hw.ac.uk

Viktor Dörfler

Department of Management Science, University of Strathclyde, Glasgow, UK, 199 Cathedral Street, G4 OQU, +44 (0)141548 4540, viktor.dorfler@strath.ac.uk

Jillian MacBryde

Department of Design, Manufacturing and Engineering Management, University of Strathclyde, Glasgow, UK, 75 Montrose St, Glasgow G1 1XJ, +44 (0) 141548 2117, jillian.macbryde@strath.ac.uk

Corresponding author: Agnessa Spanellis, Department of Business Management, Heriot Watt University, Edinburgh, UK, The Avenue, Currie EH14 4AS, +44 (0) 7563244742 , a.spanellis@hw.ac.uk 


\section{Abstract}

The increasingly popular trend of gamification has proved powerful in many areas, such as education and marketing, and has started making its way to the corporate environment. This exploratory study is focused on a particular part of corporate applications - using gamification to empower knowledge workers and to help them to interact with each other. Based on a review of the extant literature and an exploratory case study, we conceptualise different ways in which gamification supports knowledge workers and influences the dynamics of their interactions. The case study we present is that of online retailer Zappos who have been pioneers in this field. This paper is intended as the beginning of a journey towards utilising gamification in various aspects of knowledge work. Through studying the Zappos case, we draw out key learning points that can be used by other organisations in their journey to use gamification to empower knowledge workers. The paper also identifies areas for further research relevant to expert and intelligent systems, including the potential for synergies between gamification and intelligent systems, and the use of gamification in intelligent systems implementation.

Keywords: Knowledge management, gamification, knowledge workers, knowledge sharing

\section{Introduction}

Games are traditionally associated with leisure, but given how much time both children and adults spend playing games, some practitioners suggested that instead of shaming the gamers for a seemingly wasteful activity, we should learn from the games. Trying to understand what is so engaging about them, one can try replicate these features in professional environments, e.g. for empowering knowledge workers. Recently, we have seen a shift towards the perception that fun can be productive (Rey, 2014), and therefore, many businesses have started experimenting with embedding fun through game elements in business processes. In-depth analysis of such examples can help researchers to understand the features through which gamification impacts behavior of workers. 
This paper contributes to the discussion around the role of gamification in addressing some challenges of knowledge work in particular, as knowledge work is complex, is unclear what makes it productive, and therefore, the impact of gamification on knowledge workers is indirect and nuanced. Given the relatively scarce amount of implementation examples and supporting literature, we believe that an exploratory study with in-depth analysis of a single successful case can fulfil two purposes: (1) offer insights for organizations wishing to use gamification to the best effect, and (2) provide basis for researchers to formulate more precise research problems, develop better hypotheses, create more detailed models and surveys that can be subsequently rigorously tested. Thus, in this paper our conceptual argument is supported with an illustrative example of using gamification to empower knowledge workers from an exploratory case study at Zappos. This case demonstrates the ways in which gamification is embedded in the working practices of knowledge workers in this company. Building on the detailed analysis of this case in an attempt to achieve an improved understanding of the potentially rich phenomenon of the gamification of knowledge work, this paper suggests that gamification might open new frontiers to the empowerment of knowledge workers.

The potential impact of gamification on knowledge work and knowledge workers has not been explored so far in the literature at a generic level. The few studies that touch upon this topic adopt a narrow interpretation of knowledge work as knowledge manipulation (Agogué, Levillain, \& Hooge, 2015), or blend in knowledge with information (Rinc, 2014). With respect to the users, gamification is widely researched through the prism of motivation and worker engagement (Jung, Schneider, \& Valacich, 2010; Vassileva, 2012). However, the topic of motivation is deliberately downplayed it in relation to knowledge workers in this paper, because gamification can offer much more to organizations, if seen beyond a tool for motivating through playing. Among others, it has the potential to influence organizational processes and group dynamic.

Understanding the underlying features of the impact of gamification on knowledge work might be important for the future development of expert and intelligent systems, that are increasingly used to support knowledge work, in a number of ways. Firstly, embedding gamification in the design of expert and intelligent systems might help to organically implement such system in working practices, e.g. by addressing the issues of inappropriate use (González, Mora, \& Toledo, 2014). Secondly, the implementation 
of expert and intelligent systems can be supported with the use of gamification, and this potential benefit can be amplified by knowledge workers getting used to gamification more generally. The educational phase of the implementation can also be gamified, particularly using scenario-based e-learning material. For instance, gamification embedded in an intelligent tutoring system can improve engagement and usability of the system (González, Toledo, \& Muñoz, 2016). Gamified intelligent agents have already been used to support students' learning (Dyer \& Sharifi, 2020). It will not be too long, until intelligent agents and support system find their way to support knowledge workers, e.g. as supplements to corporate mentoring schemes, through the use of intelligent, context-sensitive e-learning material. Finally, learning from existing example as well understanding the impact of gamification on knowledge workers, can help to improve the adoption and use of expert and intelligent systems. It seems that gamification is often well received by knowledge workers, perhaps even if it does not perform particularly well, while often expert and intelligent systems face significant resistance, despite excellent performance. While the first-level answer is simple, i.e. nobody is afraid of games, people tend to fear thinking machines. It is not impossible that we can learn more by considering gamification and expert and intelligent systems as parallel process supporting knowledge workers.

This study examines how "game elements" are applied (either in isolation or in combination) to influence and improve particular processes and practices. As Landers (2014) suggests, this understanding will help system designers to apply gamification to a wider range of corporate applications. These observations, alone, from a single company do not warrant far-reaching conclusions. However, in this paper we combine the observations with analysis to advance our understanding of the range of gamification applications based on a working example in one company. Subsequently, this paper argues that the influence of gamification on knowledge workers may stretch beyond improved motivation and user engagement - which are the two aspects that gamification is mostly praised for (Huotari \& Hamari, 2012; Zicherman \& Cunningham, 2011; Zuckerman \& Gal-Oz, 2014). Therefore, we are trying to enrich the underlying preliminary understanding, in an attempt to formulate better problems rather than solutions.

In particular, this study explores the impact of gamification on different roles of knowledge workers and their behavioral patterns, and "visualize" various communities 
that have emerged within a company but remained unnoticed before. These observations could in turn suggest adjustments of knowledge working practices. These findings are believed to be important, because they show that gamification should be taken seriously in the context of knowledge work. Thus, this paper theorizes how gamification could become an innovation in the area of knowledge work and offers new directions for further research in the intersection of these two areas that has not been explored at necessary depth before. In this study we adopt a process view of knowledge work (Chang \& Lin, 2015; Davenport \& Prusak, 1998; Pyöriä, 2005), which is in line with considering gamification as a process. This early exploratory study opens up future research avenues including systematic surveys, and more confirmatory type methodological approaches, including testing and experiments.

The rest of the paper is structured as follows. The next section problematizes the concepts of knowledge work and knowledge worker, to prepare a conceptual ground for analyzing the case study. The second part of the literature review covers the gamification literature that informs the analysis of the exploratory case study. Then the next section of the paper presents the exploratory case study conducted in Zappos, and the observed examples of implemented elements of gamified knowledge work. Subsequently, building on this empirical study and examples from the literature, we explore the practices of knowledge workers and possibilities of using gamification to support them. The conclusions of the paper speculate about further research directions and the limitations of this study; we also discuss the numerous connection points between expert and intelligent systems and the gamification of knowledge work.

\section{Literature Review}

Below we review the literature in two distinct areas. First, we explore the notions of knowledge work and knowledge worker, in order to find a classification that can be useful for our inquiry. Then we provide a brief overview of what constitutes gamification, particularly with reference to knowledge work. The aim of this section is not to offer comprehensive review of literature in the two areas, as we are not looking for a gap in the literature. The aim is to create a conceptual framework for our analysis of a single case, as our starting point is a gap between what the literature accounts for and what we have observed in reality, in our case company. 


\subsection{Knowledge Work \& Knowledge Workers}

One of the distinguishing features of work in this century is the shift to an increased proportion of knowledge workers in the organizations. Drucker (1969) proposed that knowledge workers could constitute as much as $50 \%$ of the workers in the future, and stressed the importance of increasing their productivity as the main management challenge of the $21^{\text {st }}$ century. In facing this challenge, this study looks at the characteristics that differentiate knowledge work from manual work. Identifying these characteristics might support the claim that gamification can contribute to the productivity of knowledge workers (Morschheuser \& Hamari, 2018).

There is no complete agreement on the definition of knowledge workers in the literature, but analysis of the literature suggests an emergence of several common patterns. It is common to describe knowledge workers dealing with relatively unstructured (Scarbrough, 1999) or non-routine (Reinhardt, Schmidt, Sloep, \& Drachsler, 2011) problems, that might need symbolic-analytical skills (Reich, 1991) as well as intuition (Dörfler \& Ackermann, 2012), and require little supervision (Mintzberg, 1998). In other words, they 'think for a living' (Davenport, 2005). Furthermore, they need autonomy, continuous innovation and learning, their work is judged by quality not quantity, and it includes defining a task first, in contrast with manual work, where task are predefined (Drucker, 1999). The majority of the literature focuses on the intellectual work as representative of knowledge work. However, it is important to note that certain types of skillful manual work also fit these characteristics, because they might require high level of skills translated into expertise, e.g. chefs (Stierand, 2015). At the same time, not all non-manual workers would qualify as knowledge workers, and quite often they combine both (Drucker, 1999).

Although the above characteristics are helpful in understanding what distinguishes knowledge work from other types of work, they are located at a too high level of abstraction to help understand the ways to improve productivity of knowledge workers with emerging techniques, such as gamification (Jurado, Garces, Paredes, Segovia, \& Alavarez, 2019; Mizuyama, Yamaguchi, \& Sato, 2019). The types of knowledge work are so diverse, and so will be gamification approach to them (Friedrich, Becker, Kramer, Wirth, \& Schneider, 2020; Holzer et al., 2020). Thus, in order to analyze existing gamified knowledge work practices, it is essential to identify the types of 
knowledge workers. In turn, the approach to typology will impose limitations on generalizing the studied approach and replicating it in a different context.

There is a limited number of knowledge work classifications. Some of them focus on the on the internal characteristics of knowledge work, e.g. the need for interacting with other knowledge workers, and the characteristics of knowledge, e.g. its learnability (Davenport, 2005; Mclver, Lengnick-Hall, Lengnick-Hall, \& Ramachandran, 2013). Other classifications tend to focus on external conditions, such as organizational forms (Reed, 1996) or organizational culture (Davenport, De Long, \& Beers, 1998), which might shift the attention from the qualities of knowledge work to non-related factors.

Understanding the impact of gamification on knowledge work on a more fundamental level requires looking at the internal characteristics of knowledge work and knowledge workers. Only then, once fundamental underlying processes are identified, would it be possible to determine the variations in gamification applications dictated by the external factors, such as enterprise architecture. Furthermore, we might discover that gamification impacts external factors as much as it is influenced by them. For that reason, we focus on the classifications that deal with internal factors and roles.

The first two classifications partially overlap and are complementary to each other (Figure 1). In particular, Davenport (2005) characterized the knowledge work based on the level of collaboration required to complete the job, and the level of complexity of the work, defined by the extent to which the workers rely on their own judgement and interpretation to complete the work.

Insert Figure 1. Classifications of knowledge work

In the second framework, Mclver et al. (2013) examined 'knowledge in practice' from the perspective of tacitness (which is interpreted as the level of transferability of knowledge) and learnability (the amount of time and effort required to absorb knowledge). These two dimensions predefine the complexity of work to a degree, since more complex work is expected to take more time to learn. Therefore, the two classification partially overlap. In particular, the enacted information model that is 
characterized by relatively easy-to-learn, structured and predominantly explicit knowledge, resembles the transaction model and refers e.g. to the work in call centers. The third classification is rather different from the first two, as it does not differentiate between the types of knowledge work, but rather suggests the roles that knowledge workers might play in an organization from the perspective of their involvement in the knowing processes (Davenport \& Prusak, 1998). The two main roles are the knower and the knowledge seeker. These roles represent two sides on an interaction, whereby the interaction between the roles becomes an act of knowledge exchange. The exchange may take place only if both parties know each other, or a trusted intermediary facilitates the connection. The intermediary represents the third role - the broker. The brokers hold an imaginary knowledge map of an organization and thus are able to connect knowledge seekers and knowers.

This classification is deeply rooted in one of the fundamental knowledge practices, knowledge sharing (Oshri, Pan, \& Newell, 2006; Wang \& Wang, 2012), whereas the other two classifications indicate the extent to which various types of knowledge workers rely on this practice. Thus, this classification is different from the other two because it describes the roles that can be found in any organization.

These three models will serve as starting points for classifying gamification practices, as it is plausible that different types of knowledge work will requires different approaches if we attempt to gamify them.

\subsection{Clarifying Gamification}

The use of games for a purpose other than entertainment can be traced back to the ancient times. In 'The Histories', Herodotus says that when famine struck Lydia in Asia Minor, the king of Lydia ordered to engage in games instead of eating every other day in order to stretch the stocks of food. During this time, a lot of well-known games, such as dice, were invented (McGonigal, 2011; Rawlinson, Rawlinson, \& Willkinson, 1880). In 1902 Lizzie Magie created a game called 'The Landlord's Game' to illustrate the disadvantages of the modern land tenure system. However, this game ended up in a very different place than intended by the creator. It was bought by a company and renamed as 'Monopoly' - to become one of the best-selling board games of all times (Ferrara, 2013). In time, researchers started exploring the role of games and 
gamification in education and learning (Jorge \& Sutton, 2017; Landers, 2014; PalomoDuarte, Dodero, \& García-Domínguez, 2014), and further experiment with the use of separate game elements for non-entertainment purposes.

The early examples of introducing game elements at work can be traced back to the early Soviet Union in a form of competition between different factories (Nelson, 2012). However, embedding game elements in the non-gaming environment really took off with the development of information technology, and recently gamification also started being researched in the context of human resource management (Armstrong, Landers, \& Collmus, 2016). The elements were borrowed from games, but games, in turn, took these elements from real-life, such as military ranks, grades at schools, degrees (badges) at universities, and therefore we could say that gamification is an old concept with a new twist.

Games are usually perceived as fun. With the common purpose to make activities more engaging through fun, gamification quickly gained traction e.g. in the areas of education, marketing and sustainability (Harman, Koohang, \& Paliszkiewicz, 2014; Huber \& Röpke, 2015; Huotari \& Hamari, 2012; Zuckerman \& Gal-Oz, 2014),. The term 'gamification' was widely popularized in 2010 , when researchers and practitioners started questioning whether one could embed game elements into ordinary processes and make them more game-like. Since then many interesting application examples emerged.

However, by far not all experiments of gamification were successful. A lot of the existing applications are still reward oriented (Deterding, Dixon, Khaled, \& Nacke, 2011; Heeter, Lee, Medler, \& Magerko, 2011) and therefore rely on external regulation (Ryan \& Deci, 2000), which contradicts the essence of what makes games engaging. It is still not clear, whether gamified systems can have a sustaining behavioral effect over longer term (Hamari, 2013; Nicholson, 2012). Reward-based systems in particular have a risk of becoming an "exploitationware" (Bogost, 2011) or a surveillance tool, that tricks users into completing undesirable tasks (Cohen, 2016). However, negative examples are often the result of poor implementation rather than flaw of the gamification concept, where the design of a system is reduced to 'pointification' (Werbach \& Hunter, 2012) by a meaningless use of elements like points and badges. 
The early definitions of gamification were narrowly focused on adding game experience to electronic transactions. The understanding of the concept has since been developed to emphasize the use of game elements (Burke, 2012; Deterding et al., 2011; Werbach \& Hunter, 2012; Zicherman \& Cunningham, 2011) in order to engage users (Burke, 2012; Huotari \& Hamari, 2012; Zicherman \& Cunningham, 2011) in a non-gaming environment (Burke, 2012; Deterding et al., 2011; Werbach \& Hunter, 2012).

Analyzing a gamified system requires understanding of its components, namely game elements, their structure and the key characteristic of gamification. A variety of game elements classifications have offered taxonomies of the elements (Blohm \& Leimeister, 2013; Deterding et al., 2011; Werbach \& Hunter, 2012; Zicherman \& Cunningham, 2011). Many frameworks are based on a commonly accepted MDA (Mechanics, Dynamics, Aesthetics) model, developed for game design (Hunicke, LeBlanc, \& Zubek, 2004), however, most of them interpret incorrectly the levels of this model (see Shpakova, Dörfler, \& MacBryde, 2017 for more detail).

For that reason, this study employs the classification of Werbach and Hunter (2012) which correctly identifies the differences between game systems and gamification systems, and implications that has on the view of elements within gamified systems. This framework defines three levels (Figure 2): components as building blocks (e.g. badges and points), mechanics as a link between components and various actions that users can perform (e.g. gifting and rewarding), and dynamics, or the nature of interactions between the users (e.g. competition or progression). The aim of this paper is not to give an exhaustive classification of the elements, but rather to examine the examples of implementation that already exist, and the above classification helps to recognize these examples in a company that does not refer to them as gamification.

Insert Figure 2. Classification of gamification elements. Source: Werbach and Hunter, 2012

The most commonly used elements include points, badges and rewarding. They have been praised by game designers for being uniform and easy to implement. For 
instance, points are used for keeping the score and identifying the winning state, tracking skills/reputation, as redeemable or 'karma points' (Zicherman \& Cunningham, 2011). Badges are quite often complementary to points and usually symbolize and visualize a status gained as a result of an accomplishment (Werbach \& Hunter, 2012). But they also function as an instruction tool for the types of activities that can be performed, a display of reputation or group identification (Antin \& Churchill, 2011), a collectible, or a certification stamp (Werbach \& Hunter, 2012). Rewarding mechanic actions the above elements and helps to acknowledge and praise the achievements, e.g. by giving points or badges. Though rewards are often associated with tangible items, such forms of rewarding as a social endorsement can also be very powerful (Montola, Nummenmaa, Lucero, Boberg, \& Korhonen, 2009; Werbach \& Hunter, 2012). These and other elements are used to identify gamification examples in the case study.

\section{Methodological considerations}

The aim of this study is to explore the practices of gamifying knowledge work. As such, our objectives are in the area of finding out possible features and thus achieving an initial, possibly partial but rich, understanding of observed phenomena. The purpose of the study does not cover providing a solution, the purpose is to enable a better problem formulation. To this end, a qualitative exploratory case study was chosen to study the ways in which gamification might empower knowledge workers. The empirical material included primary data from semi-structured interviews with Zappos employees, and secondary data from the blog ZapposInsight ${ }^{1}$. This approach was developed, because a lot can be learned from an in-depth study of a 'good' example. Of course, such study will not allow for generalization, for delineating what leads to success vs failure, for mapping our necessary and/or sufficient conditions. What can be achieved is a tentative set of features that may appear in some successful implementations, and therefore should be considered for a good problem formulation in more rigorous confirmatory type research projects. We do not test the Zappos case,

\footnotetext{
${ }^{1}$ http://www.zapposinsights.com/blog.
} 
we simply observe and theorize on the basis of what we see, in order to achieve some insights that will inform further research.

Zappos is an online shoes and accessories shop operating in the U.S., established in 1999 and acquired by Amazon in 2009. The company is famous for its customeroriented service, such as special return shipping assistance, or surprise free upgrades to overnight shipping. For instance, the 'Ask Zappos' service promises to find a pair of shoes matching the photo sent by the customer, and to do it within 24 hours. However, the company is most famous for its fun-oriented corporate culture. It can be characterized as task culture, highly adaptable and focused on getting the job done (Handy, 1976), and this flexibility is enhanced with the element of fun. In 2009 Zappos featured in Fortune's Top 100 companies to work for and has not left the list since. This fact, as well as the unique organizational culture and structure that allowed for riskier experimenting with gamification, made Zappos an interesting case to search for meaningful examples of implementing game elements in the corporate environment, particularly in knowledge work. Naturally, Zappos' success cannot be solely attributed to gamification, but gamification is arguably a part of it.

\subsection{Data collection}

Data were collected form the corporate blog and through conducting interviews with Zappos employees providing a good balance between accepted facts and opinions. The blog gave insights from the employees about their everyday work, and provided examples of several gamification elements, which evidenced the use of gamification internally. The blog also served as an input to the interviews. Interviewees were chosen with varying experience and from different departments, i.e. sales, procurement, HR, customer loyalty and technical support. This allowed for the investigation of a wider area of working activities in the company, the similarities and differences in the working practices and the working environment. Thus, the gathered material provided a holistic view of the work in this company. Semi-structured interviews opened up possibilities for not only discussing the insights from the blog but also exploring other practices and experiences of people engaged in these practices. Furthermore, the semi-structured nature of the interviews allowed for the extraction of the deep insights from the interviewees and at the same time makes the interviews comparable (Saunders, Lewis, \& Thornhill, 2019). The interviews were conducted via 
Skype, transcribed, anonymized and coded in NVivo. Zappos does not use the term 'gamification' to describe its various work practices, therefore the interviewees were asked about their everyday working practices, their corporate culture, aspects of environment that they like and the initiatives that were mentioned in the blog. Earlier interviews informed the subsequent ones, and certain level of repetition increases the robustness of data.

\subsection{Data analysis}

The analysis was drawn from 5 semi-structured interviews and 80 blog posts (all the posts that were available at the time of the research). The number of interviews required to build a robust theoretical contribution in qualitative research is much less discussed in the methodology literature than the sample size for statistical analysis (Robinson, 2014), and it can be expected that the nature of the theoretical contribution also makes a difference. The number of in-depth interviews is expected to be smaller (Crouch \& McKenzie, 2006), and the requirement for achieving a set number of interviews or providing evidence of data saturation might be inappropriate (Saunders \& Townsend, 2016), as it imposes a frame alien to qualitative research in order to fit it into a world dominated by the laws of statistics (Pratt, 2008). Given the exploratory nature of this study, the number of interviews seemed sufficient as it provided interesting insights.

The analysis was based on the Gioia (2004) method, establishing "first order" themes from the interviewee's perspective and interpreting them through the "second order" themes from the authors' perspective, emerging from the conversation, and achieving new insights. The Gioia approach is used to build a 'grounded theory', meaning that the theoretical contribution is achieved by interpreting the data grounded in a new phenomenon observed in practice. Although grounded theory has its origins in positivist science, more recently it is used to study the context, understandings and meanings of the participants, based on interpretivist philosophical underpinnings. The Gioia method has become the 'go to' method for analyzing semi-structured interviews in an interpretivist farming. The interpretivist stance is fully in line with our exploratory study, and the Gioia method allowed us to immerse ourselves in the single case, achieve a 
deep understanding or its rich context, and find the logical connections in the contextually rich empirical material by interpreting the second order themes emergent from the data (Gioia, 2004; Gioia, Corley, \& Hamilton, 2013; Langley \& Abdallah, 2011).

Gioia method includes a two-stage process. First, the empirical material was examined for relevant information that are then "coded" with nodes. The codes were predominantly defined in advance, based on the reviewed literature while additional ones emerged as the analysis progressed. Then, the emergent nodes were aggregated into parental nodes, and each parent note was analysed and interpreted as a distinctive pattern. Each pattern helped to form insights about the studied phenomenon. The results were sent to two interviewees for participant validation and they found them sensible.

\section{Findings}

The analyzed case demonstrates numerous examples of game elements that are integrated in knowledge work processes. This allowed the authors to identify ways in which game elements supported different types of knowledge workers discussed in the literature review. The interviewees actively engaged with badges, points, rewarding, gifting, surprises, groupings, contests and quests. Each element is described in Table 1 with supporting quotes from the interviewees.

Table 1. Description of gamification elements.

\begin{tabular}{|c|c|c|c|c|c|c|c|c|c|}
\hline $\begin{array}{l}\text { Gamifi- } \\
\text { cation } \\
\text { Ele- } \\
\text { ments }\end{array}$ & Details & 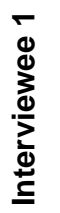 & 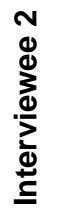 & 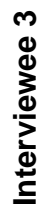 & 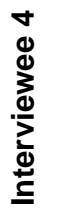 & 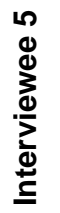 & $\frac{\text { 임 }}{\operatorname{m}}$ & Examples of quotes & $\begin{array}{l}\text { Examples of } \\
\text { similar use in } \\
\text { the literature }\end{array}$ \\
\hline \multicolumn{10}{|c|}{ Components } \\
\hline \multirow[t]{2}{*}{ Badges } & $\begin{array}{l}\text { Com- } \\
\text { pensa- } \\
\text { tion } \\
\text { badges }\end{array}$ & $X$ & $X$ & $X$ & $\mathrm{X}$ & $\mathrm{X}$ & $\mathrm{X}$ & $\begin{array}{l}\text { These are badges that } \\
\text { represent a set of } \\
\text { skills and experience } \\
\text { and are attached to } \\
\text { the compensational. }\end{array}$ & $\begin{array}{l}\text { (Ifenthaler, } \\
\text { Bellin-Mularski, } \\
\text { \& Mah, 2016) }\end{array}$ \\
\hline & $\begin{array}{l}\text { Krunky } \\
\text { badge }\end{array}$ & & $X$ & & & & & $\begin{array}{l}\text { These badges are } \\
\text { given once a month to } \\
\text { everyone for repre- } \\
\text { senting one of the } \\
\text { core values based on } \\
\text { peer assessment. }\end{array}$ & $\begin{array}{l}\text { (Antin \& } \\
\text { Churchill, 2011; } \\
\text { Holzer et al., } \\
2020 \text { ) }\end{array}$ \\
\hline
\end{tabular}




\begin{tabular}{|c|c|c|c|c|c|c|c|c|c|}
\hline & $\begin{array}{l}\text { Fun } \\
\text { badges }\end{array}$ & & & & & $x$ & & $\begin{array}{l}\text { They can be created } \\
\text { by and given to any- } \\
\text { one for anything. }\end{array}$ & $\begin{array}{l}\text { (Pedro, Santos, } \\
\text { Aresta, \& } \\
\text { Almeida, 2015) }\end{array}$ \\
\hline & $\begin{array}{l}\text { Skill } \\
\text { badges }\end{array}$ & $x$ & & & & $x$ & & $\begin{array}{l}\text { These badges repre- } \\
\text { sent a set of skills an } \\
\text { employee has, and } \\
\text { are usually given at } \\
\text { the end of a training. }\end{array}$ & $\begin{array}{l}\text { (Abramovich, } \\
\text { Schunn, \& } \\
\text { Higashi, 2013; } \\
\text { Amano, } \\
\text { Tsuzuku, } \\
\text { Suzuki, \& } \\
\text { Hiraoka, 2017; } \\
\text { Ifenthaler et al., } \\
\text { 2016) }\end{array}$ \\
\hline \multirow[t]{3}{*}{ Points } & $\begin{array}{l}\text { People } \\
\text { points }\end{array}$ & & $x$ & & & & & $\begin{array}{l}\text { They represent em- } \\
\text { ployee's time which is } \\
\text { allocated to different } \\
\text { circles. } \\
\text { Whatever circle you're } \\
\text { in, if you're not putting } \\
\text { enough time to your } \\
\text { circle, they can move } \\
\text { you from the circle. }\end{array}$ & - \\
\hline & $\begin{array}{l}\text { Power } \\
\text { points }\end{array}$ & & & & & $x$ & & $\begin{array}{l}\text { They are a reward for } \\
\text { contributing to work } \\
\text { when there is a high } \\
\text { need (e.g. busy } \\
\text { hours). }\end{array}$ & $\begin{array}{l}\text { (Morschheuser, } \\
\text { Hamari, Koivisto, } \\
\text { \& Maedche, } \\
\text { 2017; } \\
\text { Warmelink, } \\
\text { Koivisto, Mayer, } \\
\text { Vesa, \& Hamari, } \\
\text { 2020) }\end{array}$ \\
\hline & Zollars & $x$ & & $x$ & $x$ & $x$ & $x$ & $\begin{array}{l}\text { They are an internal } \\
\text { currency that is re- } \\
\text { warded for doing } \\
\text { something good and } \\
\text { can be exchanged for } \\
\text { corporate goods or do- } \\
\text { nated to a charity. }\end{array}$ & $\begin{array}{l}\text { (Scheiner, 2015; } \\
\text { Zicherman \& } \\
\text { Cunningham, } \\
\text { 2011) }\end{array}$ \\
\hline \multicolumn{10}{|c|}{ Mechanics } \\
\hline \multirow[t]{3}{*}{$\begin{array}{l}\text { Re- } \\
\text { ward- } \\
\text { ing }\end{array}$} & $\begin{array}{l}\text { co-worker } \\
\text { bonus }\end{array}$ & & $x$ & & & $x$ & $x$ & $\begin{array}{l}\text { Once a month each } \\
\text { employee is allowed to } \\
\text { give a } \$ 50 \text { bonus to } \\
\text { anyone they want to } \\
\text { with the explanation of } \\
\text { the reason and one of } \\
\text { the core values at- } \\
\text { tached to it. }\end{array}$ & $\begin{array}{l}\text { (Pedro et al., } \\
\text { 2015; Rapp, } \\
\text { 2017) }\end{array}$ \\
\hline & $\begin{array}{l}\text { Hero } \\
\text { Award }\end{array}$ & & & & & & $x$ & $\begin{array}{l}\text { The Zappos HERO } \\
\text { Award works in con- } \\
\text { junction with the Co- } \\
\text { worker Bonus Pro- } \\
\text { gram. The heroes are } \\
\text { nominated by employ- } \\
\text { ees and chosen by the } \\
\text { leadership team. }\end{array}$ & $\begin{array}{l}\text { (Hsu, Chang, \& } \\
\text { Lee, 2013; } \\
\text { Rapp, 2017) }\end{array}$ \\
\hline & $\begin{array}{l}\text { Mystical } \\
\text { Egg }\end{array}$ & & & & & & $x$ & $\begin{array}{l}\text { The Mystical Egg, is a } \\
\text { peer-based award } \\
\text { passed along each }\end{array}$ & $\begin{array}{l}\text { (Gennari, } \\
\text { Melonio, \& }\end{array}$ \\
\hline
\end{tabular}




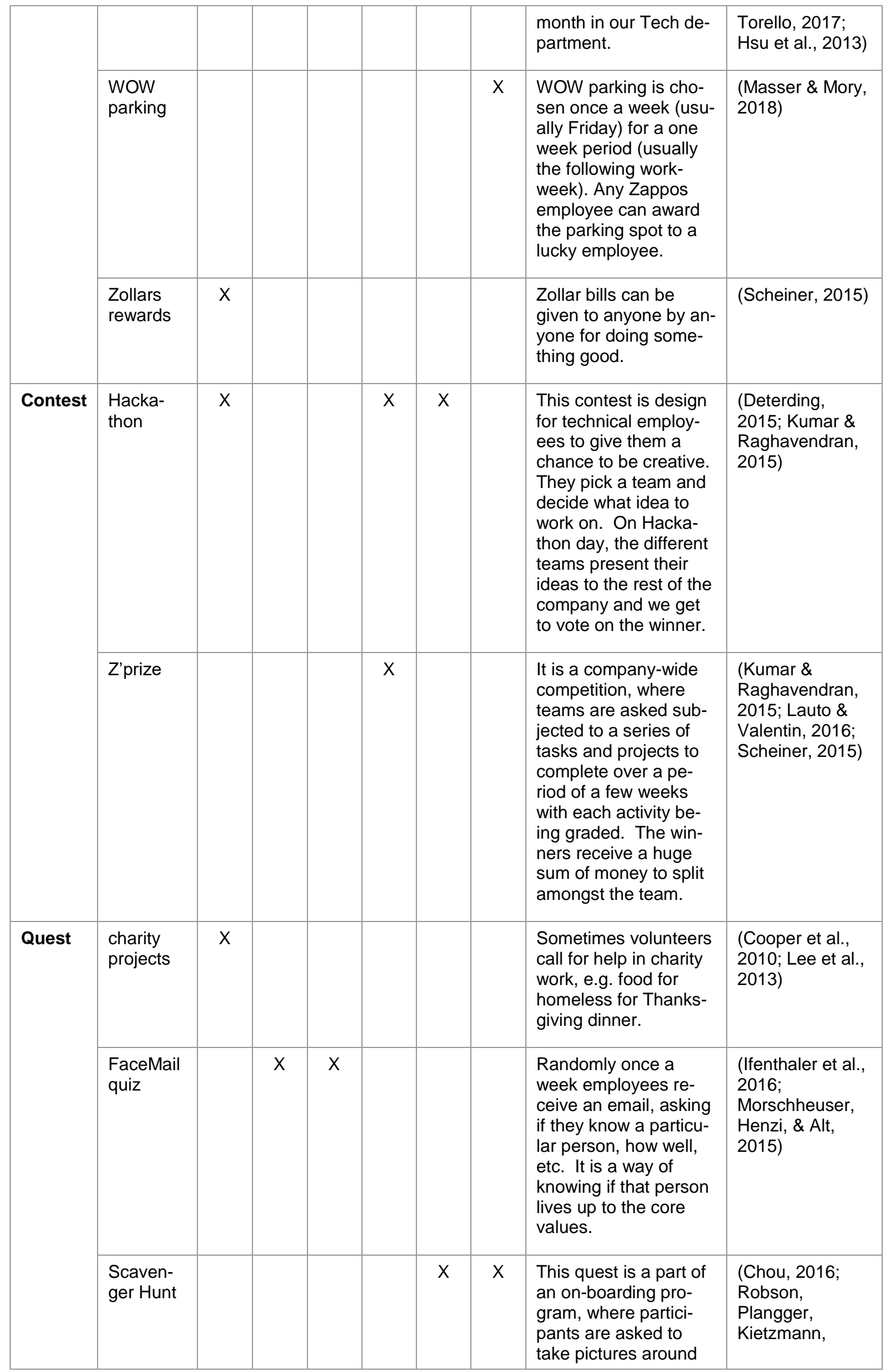




\begin{tabular}{|c|c|c|c|c|c|c|c|}
\hline & & & & & & $\begin{array}{l}\text { the campus and Las } \\
\text { Vegas downtown. This } \\
\text { helps them to bond } \\
\text { and get to know the } \\
\text { campus better. }\end{array}$ & $\begin{array}{l}\text { McCarthy, \& Pitt, } \\
\text { 2016) }\end{array}$ \\
\hline Gifting & WISHEZ & $x$ & $x$ & & $x$ & $\begin{array}{l}\text { WISHEZ platform al- } \\
\text { lows people to put on } \\
\text { their wishes and oth- } \\
\text { ers to see if they can } \\
\text { grant any particular } \\
\text { wish. }\end{array}$ & $\begin{array}{l}\text { (Chou, 2016; } \\
\text { Zicherman \& } \\
\text { Cunningham, } \\
\text { 2011) }\end{array}$ \\
\hline $\begin{array}{l}\text { Group- } \\
\text { ping }\end{array}$ & Circles & $x$ & & $x$ & & $\begin{array}{l}\text { Circles represent } \\
\text { teams and projects, } \\
\text { they show big picture } \\
\text { and allowed people to } \\
\text { follow their passions } \\
\text { on side projects. }\end{array}$ & $\begin{array}{l}\text { (Deterding, } \\
\text { 2019; Kumar \& } \\
\text { Raghavendran, } \\
\text { 2015) }\end{array}$ \\
\hline $\begin{array}{l}\text { Sur- } \\
\text { prise }\end{array}$ & $\begin{array}{l}\text { Wish } \\
\text { team }\end{array}$ & & $x$ & & & $\begin{array}{l}\text { Wish team tries to fulfil } \\
\text { the wishes that no- } \\
\text { body else grants. } \\
\text { Sometimes they try to } \\
\text { make a surprise out of } \\
\text { it, e.g. once Oasis } \\
\text { band walked to the of- } \\
\text { fice to give the re- } \\
\text { quested tickets in per- } \\
\text { son. }\end{array}$ & $\begin{array}{l}\text { (Xu, Buhalis, \& } \\
\text { Weber, 2017) }\end{array}$ \\
\hline
\end{tabular}

The identified application should be considered a good example of a gamified system not only because it incorporates game elements, but also because the elements contribute to a game-like experience. Game-like experience can be characterized through a set of attributes, namely, action language, assessment, challenge, control, environment, game fiction, human interaction, immersion, and rule/goals (Bedwell, Pavlas, Heyne, Lazzara, \& Salas, 2012). These attributes can be used to demonstrate how gamification can resemble game-like experience, e.g. in learning (Landers, 2014). Using these attributes, we can notice that elements that in their different forms comprise action language, such as points and badges, are often used for assessment, and regulated by rules, they set goals for employees, and encourage interactions through the mechanics of rewarding. Other elements, like quests and contests (e.g. Scavenger Hunt), create challenges that are combined with a narrative (game fiction) and thereby help to create an immersive experience. Finally, Zappos employees are in control of the system, because they can choose to participate and contribute to the design and environment by creating new elements (e.g. fun badges). Therefore, Zappos can be considered a good example of a gamified system. 
Most of the identified gamification examples aim to expand connections between employees and give them more opportunities to interact with each other and acknowledge contributions of each other. Moving forward from the specific examples, we link our insights from the interviews and blogposts to the body of knowledge in knowledge management (KM). In this section we theorize, on the basis of this exploratory case study, the possible application areas of gamification within the area of knowledge work, and discuss their possible benefits. To this end, the frameworks of knowledge workers are applied to the Zappos case.

\subsection{Gamification and knowledge workers}

Following from the review of knowledge work and knowledge workers, we can demonstrate that Zappos employees should be considered knowledge workers, and they fall into the transactional model of Davenport (2005) and the enacted information category of Mclver et al. (2013). The characteristics of the first classification can be observed in the employees of Zappos, which makes them knowledge workers. In particular, they have a large degree of autonomy in the job they do and decisions they make, they are encouraged to learn, and develop new approaches to work. Complementary to the first classification, the second classification helps to explain what makes this type of work less complex. Many Zappos employees work in the call center or assisting them, and thus the two models described above contribute to the understanding of the particularities and limitations of the work of the employees.

When looking at the characteristics of each category, it is possible to see that gamification helps to address their limitations. In particular, transactional model workers (Figure 1) typically do not rely on collaboration, but they could benefit from collaboration nonetheless. This model is more oriented towards individual activities and can create isolation; to overcome this isolation requires more effort. Gamification contains a number of mechanics that encourage collaboration, for example, gifting, rewarding, rating or grouping. It seems that the company understands these limitations and actively creates collaborative dynamics using the mechanics of peer-to-peer rewarding, gifting or rating through 'FaceMail' game.

With regards to the enacted information category (Figure 1), such routine-based work is relatively structured and easy to learn, which, however, may result in loss of interest and boredom. It seems that the company is likely to treat this job as a craft rather than 
a routine and views its employees leaning towards the apprenticeship category (high level of learnability and high tacitness). For example, the customer loyalty team does not have any scripts to answer the calls. They are encouraged to be creative with customers and establish a personal connection, and they have a great degree of freedom to do so. Apart from that, various departments run 'Shadow sessions' (following another person at work for several hours) in addition to or instead of trainings in order to learn about the work of others. Any employee can also become a Z'apprentice (Zappos apprentice) for six months in a different role in order to acquire new skills.

This degree of flexibility is supported by several gamification elements. Since the departments and projects have been replaced by circles (groups), it became much easier for employees to belong to several circles. In addition, the system of people points helps to formalize it by distributing the points between the circles an employee wants to be a part of.

"Circle structure has allowed people to follow their passions on side projects..." (Interviewee 4, Marketing)

Apart from that, the company organizes various ideas contests that allow them to both participate in someone else's project and pursue their own ideas.

"The Z'prize was a great example of a company-wide competition... The team who ended up winning the mock commercial was then in charge of helping create a national Zappos TV advertisement... Hackathon (ideas competition) was primarily for our Technical employees who spend a lot of their time maintaining and fixing our e-commerce infrastructure. This could give them a chance to be creative and let loose so to speak." (Interviewee 4, Marketing)

This way gamification is used as a tool to make routine work more creative.

The third framework covered in the literature review, describes the knowledge worker roles that can be found in any company (Davenport \& Prusak, 1998) including Zappos. The knowers and the seekers remain the primary roles in knowledge work. Gamification can help to make the knower more visible, e.g. through skill and competence badges that display employees' competences and prior experience, and make them more easily searchable. This in turn reduces the need for the brokers, 
whose primary role is to help knowledge seekers find knowers. However, they might still be important as knowledge workers who can facilitate new connections by making an introduction. Gamification can also help to make the brokers more visible. For instance, Zappos uses 'FaceMail' to maps social connections among their employees.

"And that it gives us the way of knowing, how many people know this person, is this person sociable, do these people trust this person, do the people like this person, can this person handle the work? And that kind of gives us a feel of whether this person lives up to the core values." (Interviewee 2, HR)

On the other hand, not everyone showed the same degree of enthusiasm about this initiative.

"Embarrassed to say that l've never tried FaceMail in all my years at Zappos. I don't have a problem getting to meet and know people, so I don't feel compelled to play the game." (Interviewee 4, Marketing)

The company visualizes and tracks achievements of the knowers with different types of badges and by rewarding helpful behavior and sharing it publicly. Encouraging such behavior cultivates the culture of mutual help with the dynamic of knowledge pull, essential for effective knowledge sharing (Wiig, 1997). Other companies introduced a system of rewards with points for certain KM-related actions (Augustin, Thiebes, Lins, Linden, \& Basten, 2016). This way the knowers can become more visible through tracking the score of their activities, such as the projects they participated in, or their comments and reviews that were praised by their colleagues. However, such systems only work if participation is voluntary, and therefore, it is inevitable, that some employees will choose not to participate, as was evident from the quote above. This and other shortcomings can never be entirely avoided, but gamifying knowledge work is a process that follows a learning curve, as is KM itself. Furthermore, a knowledge manager, who designs the environment for knowledge workers, can use gamified systems for experimentation to understand the effectiveness of the awards, statuses, and contests. The summary of the findings is included in Table 2.

Table 2. Summary of the findings.

\begin{tabular}{|c|c|c|}
\hline $\begin{array}{c}\text { Category of } \\
\text { knowledge } \\
\text { work(ers) }\end{array}$ & Characteristics and limitations & Findings \\
\hline
\end{tabular}




\begin{tabular}{|l|l|l|}
\hline $\begin{array}{l}\text { Mransactional } \\
\text { Model }\end{array}$ & $\begin{array}{l}\text { Transaction-based work with low } \\
\text { level of complexity and little } \\
\text { collaboration required. The work } \\
\text { might be lonely. }\end{array}$ & $\begin{array}{l}\text { Collaborative dynamics are actively created with the } \\
\text { mechanics of peer-to-peer rewarding with points, } \\
\text { badges and monetary rewards, which are also } \\
\text { supported with a story behind the reward, gifting } \\
\text { (WISHEZ program) or rating through 'FaceMail' game. }\end{array}$ \\
\hline $\begin{array}{l}\text { Enacted } \\
\text { Information }\end{array}$ & $\begin{array}{l}\text { Routine-based work with high } \\
\text { level of learnability and low level } \\
\text { of tacitness. Is relatively easy to } \\
\text { standardise - little room for } \\
\text { creativity. }\end{array}$ & $\begin{array}{l}\text { Employees can follow their passions by belonging to } \\
\text { several circles (fulfilling several functions) } \\
\text { simultaneously, which is easy to allocate with people } \\
\text { points. Various contests (e.g. ZPrize and Hackathon) } \\
\text { allow them to be more creative and pursue their own } \\
\text { ideas. }\end{array}$ \\
\hline $\begin{array}{l}\text { Knowledge } \\
\text { workers' roles }\end{array}$ & $\begin{array}{l}\text { Knowers and knowledge seekers } \\
\text { as the primary roles and being } \\
\text { connected by brokers. }\end{array}$ & $\begin{array}{l}\text { Various forms of badges and rewarding help to visualise } \\
\text { competences of knowers. Connectors become more } \\
\text { visible with 'FaceMail' game, and their role might shift } \\
\text { towards giving introduction. Points and mechanics of } \\
\text { rewarding and gifting might reveal new roles, e.g. } \\
\text { helpers, altruists, good decision makers etc. }\end{array}$ \\
\hline
\end{tabular}

Gamification can potentially be used to identify types of knowledge workers that are not necessarily covered by any of the above classifications. This might be a direction for further research. The company is already using power points as one of the indicators of people who make good decisions locally.

"So, I think, originally they chose the people who were fit, who were making good decisions locally. Because usually it's busy and you earn the power points... It's not completely based on them, but it's one of those criteria to see, gaining high points." (Interviewee 5, Customer Service)

Rewards can be useful in revealing helpers and altruists, those who just want to help for a "thank you" or are so passionate about their subject that they are willing to share their knowledge whenever they have a chance. Working in a transparent environment improves trust, and therefore creating a favorable environment can foster knowledge sharing (Al-Alawi, Al-Marzooqi, \& Mohammed, 2007; Davenport \& Prusak, 1998).

\subsection{Discussing the empowerment of knowledge workers}

This section is aimed at speculating about further implications, drawing out points back to the case company and the literature. The above examples illustrated some of the possibilities that gamification opens up to improve productivity of knowledge workers within specific types of knowledge work, but gamification can have broader implications; it can help to make knowledge workers feel empowered and in charge of their professional lives. In this sense, empowerment is not about delegating decisions 
but putting knowledge workers in charge of their work by default, as in Handy's (2015) principle of subsidiarity. For instance, as evidenced from the interviews, the immediate purpose of the compensation and skills badges is to show to the other employees the skills and competences that a particular person has. The availability of this information might potentially improve the transparency of skill distribution (particularly with regards to the salary) and also raises awareness of those particular skills, as well as of skills more generally, but the full impact of these elements is yet to be observed. In addition, badges might facilitate easier relocation of the employees to areas they are more interested in without fear of losing social status in the organizational hierarchy, thus giving them more power to define their unique career path. This can be achieved because the badges and associated compensation stay with them, and they are not bound with the perception of moving up, downwards and sideways their career ladders anymore. Higher mobility, in turn, may facilitate knowledge sharing across the organization. In this sense, gamification can help developing a more knowledgeoriented culture, which is a central goal of KM in any organization (Liebowitz, 2001).

Compensation badges can also generate new requirements for a particular expertise, if there is a shortage of particular skills in the company or if a new type of expertise is required. This way a company is able to find and educate local ambassadors of organizational change who are willing to and interested in acquiring new skills and therefore will help to implement this change. An organization will also be able to identify like-minded people and help the emergence of communities that could play a vital role in facilitating knowledge sharing (Pyrko, Dörfler, \& Eden, 2017). Some of these effects have already been observed in Zappos. For instance, the company has created a 'Teal' badge, which can be obtained if an employee invests time in learning about a new organizational structure and completes an assessment. Employees who have obtained this badge, can explain the main principles of the new structure to their peers and reduce fear associated with the change. In this example, the badge is used as a reward that signals the need for change and facilitates the flow of knowledge across the organization that ultimately brings cultural change. Therefore, the impact of gamification on the flow of knowledge can become another direction for further research.

With improved mobility, enabled by badges, such elements as people points and circles become a powerful tool to record and show the concentration of interest of the 
employees in certain areas. Furthermore, these badges can become sources of insights about the reasons for some areas receiving less interest, and with these insights one could find the ways to make these areas more attractive for employees. These tools can also help to organically map expertise of the employees. Further research can explore new ways of using gamification for knowledge mapping and visualization.

We have observed that knowledge workers have engaged in playful behavior and developed relationship with some of the elements, e.g. the Mystical Egg award and Krunky Badges. It is not uncommon to see that users attribute personification characteristics to, relationship developed and engage in playful behavior with gamification elements, most often with avatars (McGonigal, 2011) and mascots (Macleod, 2017; Munday, 2017). Reportedly, these relationships moved the users to engage in an activity or become more connected with the system. An ongoing discussion of the adoption and acceptance of expert and intelligent systems is fueled by the "tragic" examples of introducing human-like agents (Miller, Wolf, \& Grodzinsky, 2017). In contrast, when such intelligent agents are made more gameful with the help of game elements, e.g. a theme, such design might help to improve acceptance of intelligent systems and Al powered agents (Spanellis, 2020). One such example includes dinosaur-looking intelligent assistants in The Henn-na Hotel in Nagasaki, Japan, whom the visitors found very appealing (Osawa et al., 2017). This example suggests that gameful design might make intelligent assistants somewhat less threatening than human-like equivalents, like Microsoft's Al powered chatbot, while numerous examples of gamification applications including this study demonstrate that the users tend to develop relationship with fictional characters and other game elements. Further research in this directions can examine the potential role of gamification for expert and intelligent systems as an enabler of playful behaviour, which can result in developing relationship with gamified intelligent systems and thus improve their acceptance. In turn, one of the possible drawbacks of gamified systems is that they become boring. However, using expert and intelligent systems can enable machine learning of gamification, so that the game rules and mechanics can evolve over time.

A lot of the gamification components and mechanics support competitive dynamics, and when they are applied the competitive dynamics can occur naturally. In order to 
change it, one needs to put emphasis on other types of game elements. Zappos encourages rewarding mechanics in various forms to create collaborative dynamics with some elements of competition. In other circumstances gamification could initiate dynamics, for example, start a conversation and collaboration, especially if the knowledge workers work remotely, e.g. sales representatives. One retail company launched a game 'The hunt - reveal the secret customer', a game with code words, which were updated through intranet. Sales representatives had to incorporate them in their speech, when they greet a new customer, and in return the secret customer would reply 'I'm a mystery man' if it was them. Apart from the improved performance and increased sales the company initiated collaboration between the sales-people of different outlets, who were discussing various ways to incorporate each new word and sharing their experience (Eunen, 2015). This is yet another example that demonstrates how gamification can facilitate knowledge sharing, and urges the need for further research in this direction.

There are further ways to use gamification in a corporate environment. For instance, a company could create a platform where employees share their ideas and rate ideas of others, provide feedback and earn points for submitting ideas, commenting on them and suggesting improvements (Shpakova, Dörfler, \& MacBryde, 2019). Such system could help identify those who are good at creating new ideas, those who are good at critically evaluating or improving the ideas (Hutter, Hautz, Füller, Mueller, \& Matzler, 2011).

It is also important to note that gamification is only one of the factors contributing to the success of companies. Zappos it is also a good place to work and provides services that the customers want, amongst others. It is easy to argue that the company achieved its results largely due to its levelled organizational structure. Its informal and friendly corporate culture and values, which shape the behavior (Al-Alawi et al., 2007) and might be shaped by gamification interventions. In this company, employees come first:

"It's not the customers, but the employee that come first, because if the employees are happy, they are going to make the customers happy." (Interviewee 1, Merchandise)

"I'm lucky enough to work at a company where the people and the culture are such a good fit, that we can try new organizational structures like 
Holacracy... But that fit between people and culture is important because if one or the other is off, we wouldn't have had success implementing these various systems and programs." (Interviewee 4, Marketing)

Zappos went through a major organizational change and shifting its organizational structure towards a more decentralized form of governance called 'holacracy' (Ethan Bernstein, John Bunch, Niko Canner, \& Michael Lee, 2016) that adopts similar principles to network organizations (Santoro, Borges, \& Rezende, 2006). In this organizational structure the employees have all the responsibility and the managers are being replaced with lead-links, meaning that they do not manage anymore, do not have the final say, they rather facilitate work in the event of deadlock or help to resolve tensions (Economist, 2014). The hierarchy is being levelled, giving the way to the incentives of proactive employees, and in this environment gamification helps to accelerate change (e.g. through a 'Teal' badge). Gamification is also aligned with the corporate culture and reinforces corporate values by making them personal and helping employees to relate themselves to the company (e.g. through a 'Krunky' badge). Without the right environment, the use of gamification would not have been so powerful. On the other hand, gamification becomes an essential component of translating organizational culture (e.g. through badges and points linked to core values) and shaping the structure (e.g. through circles). Thus separating the impact of gamification specifically from other aspects of organizational environment would be impossible.

Gamification is praised for improving motivation and user engagement, and the topic of motivation was extensively researched in the field of KM. This paper deliberately avoided this topic, primarily because this study can demonstrate the reach and potential usefulness of gamification that go far beyond motivation. In addition, trying to motivate demotivated people with games is similar to trying to treat the symptoms instead of finding the cause of an illness. Similarly, managers in Zappos think, that:

"Motivation is necessary; however, when I feel that I need to motivate myself, it's usually to do something that I really didn't want to do in the first place. It may seem that motivation is a good thing, and it is, if it's coming from the right place." (ZapposInsights) 


\section{Conclusions}

This paper presents an early exploratory study about the ways in which gamification could be used in knowledge work. In particular, it examines the characteristics and limitations of particular types of knowledge workers and demonstrates how gamification can address these limitations. For knowledge workers whose work does not depend on collaboration, it can facilitate more collaboration. It can also make an environment more creative for a routine work that might be considered rather boring otherwise. Additionally, gamification can help to make different knowledge workers' roles more visible in the company and even identify new roles. Apart from that, it can visualize their skills and even create requirements for new skills that the workers will notice. It can also show the dynamics of interactions between the knowledge workers and influence it.

These findings are significant, because they open a new problem area for additional discussion and conceptualization of the roles of gamification in knowledge work. However, this paper is based mostly on secondary data, a few interviews and the scarce extant literature, which was supplemented with speculation leading to tentative ideas. It is therefore clear that further empirical studies need to be conducted in order to further explore the ideas and suggest solutions to making use of gamification in the corporate environment generally and in KM specifically. Furthermore, as the field of gamification is relatively new, subsequent research could also reveal new ways in which organizations could benefit from gamification. The findings can be used by other researchers as an input for more systematic surveys and more confirmatory type methodological approaches.

The case study presented in this paper, can help practitioners to find opportunities for introducing gamification to the knowledge work. We are still far from finding a generally applicable solutions, and solutions are likely to be different for different companies. However, we can see that gamification can better connect knowledge workers and provide tools for more autonomy.

Our findings also have relevance to policy-makers. Some of the essential game elements that were used in the above examples are points and badges, and labor legislation in different countries can have varying implication on the application of these components and actions. For instance, in the US accumulated points can be 
integrated in employees' assessment, whereas in Germany or Austria the use of these components and actions is much more restricted by law due to the protection of a person's wellbeing and creating equal working conditions (Zimmerling, Hoflinger, Sandner, \& Welpe, 2016). As an immediate implication, this consideration adds constrains to a system design. The long-term implications might suggest changes in the legislation in certain countries, if these game elements prove to be the key to successfully gamifying business process and improving the productivity potential of the knowledge-intensive companies. Thus, our findings also open a new area for further research in policy-making.

Although it was not in the focus of the current study we have identified a number of connection points and multiple dimensions of relevance to the areas of expert and intelligent systems. Perhaps the most immediate point is that as both gamification as well as expert and intelligent systems are used to support knowledge work. Both of them tend to be highly computer-based, they need to be aware of each other, and achieving synergies between gamification and expert and intelligent systems seems to be a major further research avenue in the area of knowledge work. One interesting research problem here is whether different types of knowledge work can be differently supported by expert and intelligent systems and whether what was described about gamification in the paper can serve as useful starting point. In addition, there are, additional points, resulting from applying gamification to expert and intelligent systems and vice versa. Gamifying expert and intelligent systems can potentially lead to better implementations, reduced and improved learning experience, and gamification might help overcome some limitations or problems of expert and intelligent systems similar to how it can help in knowledge work. Conversely, one of the great challenges of gamification is how to keep up the interest, and expert and intelligent systems can help developing intelligent and/or evolving games that can adapt to different contexts, develop over time, reflect the skills of knowledge workers, and so forth. Therefore, we believe that gamification and expert and intelligent systems will develop into a research area in its own right.

This paper has a number of limitations. Although this study made a great use of the successful implementation example of gamification in the corporate environment by Zappos, the conclusions are based only on one successful case, and therefore this example should not be treated as a secret key to success. Instead, it should be treated 
as an example of good gamification, demonstrating that it is possible - but how gamification can be useful depends on many factors that we are only beginning to understand.

Furthermore, this study does not elaborate on important criteria such as cultural (Rimon, 2015), age (Hartmann \& Klimmt, 2006; Williams, Consalvo, Caplan, \& Yee, 2009) and gender (Coppens, 2015) differences that are being explored in the field of gamification and that will have an impact on the ways it could be used in corporate environments. All of these questions could not be possible covered in a single paper, partially due to the length limitations, partially due to the novelty of this research area. But this is what makes the contribution of this paper significant - it steps on a virgin field and opens a wide range of new areas for further research.

Additionally, the use of gamification is only one factor contributing to the success of the company. As was noted in the discussion, Zappos also has a unique organizational culture and a levelled structure, which allow gamification to thrive. At the same time, gamification helps to reinforce the culture and not only support but also further develop the structure (circles). The synergy between these aspects might be an interesting theme to explore further.

Another interesting area with potential for future research is the relationship between gamification and playfulness. The Zappos experience demonstrates that playfulness can create a favorable environment for gamification. Employees can express themselves by drawing graffiti on the walls, bringing staffed animals and turning the office into a zoo or organizing theme parties. Scholars started investigating the role of playing at work (Petelczyc, Capezio, Wang, Restubog, \& Aquino, 2018) in parallel with gamification. These two streams of research are similar to the distinction between paidia and ludus (Deterding et al., 2011), and it seems that in Zappos they coexist successfully and reinforce one another. Therefore, this synergy between gamification and playfulness could be another potential further direction of research.

\section{Acknowledgements}

We would like to thank Airida Jon (a merchandise specialist from Zappos) for helping to organise interviews with the company and all the participants of this study for 
committing their precious time and leading us to very useful insights about the work in their company.

\section{References}

Abramovich, S., Schunn, C., \& Higashi, R. M. (2013). Are badges useful in education?: It depends upon the type of badge and expertise of learner. Educational Technology Research and Development, 61(2), 217-232. https://doi.org/10.1007/s11423-013-9289-2

Agogué, M., Levillain, K., \& Hooge, S. (2015). Gamification of Creativity: Exploring the Usefulness of Serious Games for Ideation. Creativity \& Innovation Management, 24(3), 415-429. https://doi.org/10.1111/caim.12138

Al-Alawi, A. I., Al-Marzooqi, N. Y., \& Mohammed, Y. F. (2007). Organizational culture and knowledge sharing: critical success factors. Journal of Knowledge Management, 11(2), 22-42. https://doi.org/10.1108/13673270710738898

Amano, K., Tsuzuku, S., Suzuki, K., \& Hiraoka, N. (2017). Designing a Digital Badge as a Reflection Tool in Blended Workshops. The Journal of Information and Systems in Education, 16(1), 12-17. https://doi.org/10.12937/ejsise.16.12

Antin, J., \& Churchill, E. (2011). Badges in social media: A social psychological perspective. In Chi 2011 (pp. 1-4). Vancouver, BC.

Armstrong, M. B., Landers, R. N., \& Collmus, A. B. (2016). Gamifying Recruitment, Selection, Training, and Performance Management: Game-Thinking in Human Resource Management. In H. Gangadgarbatla \& D. Z. Davis (Eds.), Emerging Research and Trends in Gamification (pp. 140-165). Hershey PA: Information Science Reference. https://doi.org/10.4018/978-1-4666-8651-9.ch007

Augustin, K., Thiebes, S., Lins, S., Linden, R., \& Basten, D. (2016). Are We Playing Yet? a Review of Gamified Enterprise Systems. In PACIS 2016 Proceedings (pp. 1-15). Chiayi, Taiwan.

Bedwell, W. L., Pavlas, D., Heyne, K., Lazzara, E. H., \& Salas, E. (2012). Toward a taxonomy linking game attributes to learning: An empirical study. Simulation and Gaming, 43(6), 729-760. https://doi.org/10.1177/1046878112439444

Blohm, I., \& Leimeister, J. M. (2013). Gamification: Design of IT-based enhancing services for motivational support and behavioral change. Business and Information Systems Engineering, 5(4), 275-278. https://doi.org/10.1007/s12599-013-0273-5

Bogost, I. (2011). Persuasive Games: Exploitationware. Retrieved August 17, 2015, from http://www.gamasutra.com/view/feature/6366/persuasive_games_exploitationware.php

Burke, B. (2012). Gamification 2020: What Is the Future of Gamification? Retrieved from https://www.gartner.com/doc/2226015/gamification--future-gamification

Chang, C. L. hsing, \& Lin, T. C. (2015). The role of organizational culture in the knowledge management process. Journal of Knowledge Management, 19(3), 433-455. https://doi.org/10.1108/JKM-08-2014-0353

Chou, Y.-K. (2016). Actionable gamification: Beyond points, badges, and leaderboards. Octalysis Media. Victoria, British Columbia, Canada: Leanpub. https://doi.org/10.1017/CBO9781107415324.004

Cohen, J. E. (2016). The Surveillance-Innovation Complex: The Irony of the Participatory Turn. In I. D. Barney, G. Coleman, C. Ross, J. Sterne, \& T. Tembeck (Eds.), The Participatory Condition in the Digital Age (pp. 1-14). Minneapolis, MN: University of Minnesota Press.

Cooper, S., Khatib, F., Treuille, A., Barbero, J., Lee, J., Beenen, M., ... Players, F. (2010). 
Predicting protein structures with a multiplayer online game. Nature, 466, 756-760. https://doi.org/10.1038/nature09304

Coppens, A. (2015). Feminine gamification viewpoint: Social conversations. Retrieved September 22, 2015, from http://gamificationnation.com/?s=tone+of+communication

Crouch, M., \& McKenzie, H. (2006). The logic of small samples in interview-based qualitative research. Social Science Information, 45(4), 483-499. https://doi.org/10.1177/0539018406069584

Davenport, T. H. (2005). Thinking for a living : how to get better performance and results from knowledge workers. Boston, Mass.: Harvard Business School Press.

Davenport, T. H., De Long, D. W., \& Beers, M. C. (1998). Successful Knowledge Management Projects. Sloan Management Review, 32(2), 43-57.

Davenport, T. H., \& Prusak, L. (1998). Working knowledge : how organizations manage what they know. Boston, Mass.: Harvard Business School Press.

Deterding, S. (2015). The Ambiguity of Games: Histories and Discourses of a Gameful World. In S. P. Walz \& S. Deterding (Eds.), The Gameful World. Approaches, Issues, Applications (pp. 23-64). Boston, MA: MIT Press.

Deterding, S. (2019). Gamification in Management: Between Choice Architecture and Humanistic Design. Journal of Management Inquiry, 28(2), 131-136. https://doi.org/10.1177/1056492618790912

Deterding, S., Dixon, D., Khaled, R., \& Nacke, L. (2011). From game design elements to gamefulness. In Proceedings of the 15th International Academic MindTrek Conference on Envisioning Future Media Environments - MindTrek '11 (pp. 1-7). Tampere, Finland. https://doi.org/10.1145/2181037.2181040

Dörfler, V., \& Ackermann, F. (2012). Understanding intuition: The case for two forms of intuition. Management Learning, 43(5), 545-564. https://doi.org/10.1177/1350507611434686

Drucker, P. F. (1969). The Age of Discontinuity. London: Butterworth-Heinemann Ltd.

Drucker, P. F. (1999). Management challenges for the 21 st century. Oxford: Routledge.

Dyer, R., \& Sharifi, H. (2020). Overview of AI initiatives (HE) to date \& general dialogue on current state of market \& opportunities. In Presentation at the Artificial Intelligence Initiative. Liverpool, UK: Risk Institute, University of Liverpool. Retrieved from https://riskinstitute.uk/events/aiinitiative/

Economist. (2014, July 5). The Holes in Holacracy; Schumperter. The Economist, p. 56. https://doi.org/http://dx.doi.org/10.1108/17506200710779521

Ethan Bernstein, John Bunch, Niko Canner, \& Michael Lee. (2016). Beyond the Holacracy Hype. Harvard Business Review, Jul-Aug, 1. Retrieved from https://hbr.org/2016/07/beyond-the-holacracy-hype

Eunen, M. Van. (2015). Presentation at GHC14. In GWC14. Barcelona. Retrieved from https://youtu.be/R1_PQiRqIrg

Ferrara, J. (2013). Games for Persuasion: Argumentation, Procedurality, and the Lie of Gamification. Games and Culture, 8(4), 289-304. https://doi.org/10.1177/1555412013496891

Friedrich, J., Becker, M., Kramer, F., Wirth, M., \& Schneider, M. (2020). Incentive design and gamification for knowledge management. Journal of Business Research, 106, 341-352. https://doi.org/10.1016/j.jbusres.2019.02.009

Gennari, R., Melonio, A., \& Torello, S. (2017). Gamified probes for cooperative learning: a case study. Multimedia Tools and Applications, 76(4), 4925-4949. https://doi.org/10.1007/s11042-016-3543-7

Gioia, D. A. (2004). A renaissance self: Prompting personal and professional revitalization. In R. E. Stablein \& P. J. Frost (Eds.), Renewing research practice: Scholars' journeys (pp. 
97-114). Stanford, CA: Stanford University Press.

Gioia, D. A., Corley, K. G., \& Hamilton, A. L. (2013). Seeking Qualitative Rigor in Inductive Research. Organizational Research Methods, 16(1), 15-31. https://doi.org/10.1177/1094428112452151

González, C., Mora, A., \& Toledo, P. (2014). Gamification in intelligent tutoring systems. In TEEM '14: Second International Conference on Technological Ecosystems for Enhancing Multiculturality (pp. 221-225). Salamanca, Spain. https://doi.org/10.1145/2669711.2669903

González, C., Toledo, P., \& Muñoz, V. (2016). Enhancing the Engagement of Intelligent Tutorial Systems through Personalization of Gamification. International Journal of Engineering Education, 32(1), 532-541.

Hamari, J. (2013). Transforming homo economicus into homo ludens: A field experiment on gamification in a utilitarian peer-to-peer trading service. Electronic Commerce Research and Applications, 12(4), 236-245. https://doi.org/10.1016/j.elerap.2013.01.004

Handy, C. B. (1976). So you want to change your organisation? Then first identify its culture. Management Learning, 7(2), 67-84. https://doi.org/10.1177/135050767600700202

Handy, C. B. (2015). The second curve: Thoughts on reinventing society. London: Random House.

Harman, K., Koohang, A., \& Paliszkiewicz, J. (2014). Scholarly interest in gamification: a citation network analysis. Industrial Management \& Data Systems, 114(9), 1438-1452.

Hartmann, T., \& Klimmt, C. (2006). Gender and computer games: Exploring females' dislikes. Journal of Computer-Mediated Communication, 11(4), 910-931. https://doi.org/10.1111/j.1083-6101.2006.00301.x

Heeter, C., Lee, Y., Medler, B., \& Magerko, B. (2011). Beyond player types: gaming achievement goal. In 2011 ACM SIGGRAPH symposium on video games - Sandbox '11 (pp. 43-48). New York. https://doi.org/10.1145/2018556.2018565

Holzer, A., Kocher, B., Bendahan, S., Vonèche Cardia, I., Mazuze, J., \& Gillet, D. (2020). Gamifying knowledge sharing in humanitarian organisations: a design science journey. European Journal of Information Systems, 00(00), 1-19. https://doi.org/10.1080/0960085X.2020.1718009

Hsu, S. H., Chang, J.-W., \& Lee, C.-C. (2013). Designing attractive gamification features for collaborative storytelling websites. Cyberpsychology, Behavior and Social Networking, 16(6), 428-435. https://doi.org/10.1089/cyber.2012.0492

Huber, S., \& Röpke, K. (2015). How Gamification Can Help Companies to Become More Sustainable: A Case Study on Ride Sharing. In T. Reiners \& L. C. Wood (Eds.), Gamification in Education and Business (pp. 615-636). Heidelberg: Springer. https://doi.org/10.1007/978-3-319-10208-5

Hunicke, R., LeBlanc, M., \& Zubek, R. (2004). MDA: A formal approach to Game Design and Game Research. In Proc. AAAI workshop on Challenges in Game (pp. 1-5). Menlo Park, California: AAAI Press.

Huotari, K., \& Hamari, J. (2012). Defining Gamification - A Service Marketing Perspective. In Proceedings of the 15th International Academic MindTrek Conference: Envisioning Future Media Environments (pp. 17-22). Tampere, Finland. https://doi.org/10.1145/2393132.2393137

Hutter, K., Hautz, J., Füller, J., Mueller, J., \& Matzler, K. (2011). Communitition: The Tension between Competition and Collaboration in Community-Based Design Contests. Creativity \& Innovation Management, 20(1), 3-21. https://doi.org/10.1111/j.14678691.2011.00589.x

Ifenthaler, D., Bellin-Mularski, N., \& Mah, D.-K. (2016). Foundation of Digital Badges and Micro-Credentials: Demonstrating and Recognizing Knowledge and Competencies. (D. 
Ifenthaler, N. Bellin-Mularski, \& D.-K. Mah, Eds.). Switzerland: Springer International Publishing. https://doi.org/10.1007/978-3-319-15425-1_26

Jorge, C. F. B., \& Sutton, M. J. D. (2017). FUNIFICATION 2.0: knowledge mobilization model for corporate and educational game-based learning. World Journal of Science, Technology and Sustainable Development, 14(2/3), 84-110. https://doi.org/10.1108/WJSTSD-112016-0060

Jung, J. H., Schneider, C., \& Valacich, J. (2010). Enhancing the Motivational Affordance of Information Systems: The Effects of Real-Time Performance Feedback and Goal Setting in Group Collaboration Environments. Management Science, 56(4), 724-742. https://doi.org/10.1287/mnsc.1090.1129

Jurado, J. L., Garces, D. F., Paredes, L. M., Segovia, E. R., \& Alavarez, F. J. (2019). Model for the Improvement of Knowledge Management Processes Based on the Use of Gamification Principles in Companies in the Software Sector. In J. Mejia, A. Peña, M. Muñoz, M. PérezCisneros, \& Á. Rocha (Eds.), Trends and Applications in Software Engineering (pp. 142151). Cham: Springer Nature Switzerland AG. https://doi.org/10.1007/978-3-319-262857

Kumar, H., \& Raghavendran, S. (2015). Gamification, the finer art: fostering creativity and employee engagement. Journal of Business Strategy, 36(6), 3-12. https://doi.org/10.1108/JBS-10-2014-0119

Landers, R. N. (2014). Developing a Theory of Gamified Learning: Linking Serious Games and Gamification of Learning. Simulation and Gaming, 45(6), 752-768. https://doi.org/10.1177/1046878114563660

Langley, A., \& Abdallah, C. (2011). Templates and turns in qualitative studies of strategy and management. In D. D. Bergh \& D. J. KetchenJr. (Eds.), Building Methodological Bridges (Vol. 6, pp. 105-140). Bingley: Emerald Group Publishing. https://doi.org/10.1108/S1479-8387(2011)0000006007

Lauto, G., \& Valentin, F. (2016). How preference markets assist new product idea screening. Industrial Management \& Data Systems, 116(3), 603-619. https://doi.org/10.1108/IMDS07-2015-0320

Lee, J. J., Marks, J., Matamoros, E., Luna, C. de, Kern, R., \& Jordan-Cooley, W. (2013). Greenify: Fostering Sustainable Communities Via Gamification. In CHI 2013 Extended Abstracts (pp. 1497-1501). Paris. https://doi.org/10.1145/2468356.2468623

Liebowitz, J. (2001). Knowledge management and its link to artificial intelligence. Expert Systems with Applications, 20, 1-6. https://doi.org/10.1016/S0957-4174(00)00044-0

Macleod, C. (2017). Duolingo: A Tool to Supplement Language Learning at University. In Communication in Culture (Vol. 11, pp. 167-177).

Masser, K., \& Mory, L. (2018). The Gamification of Citizens' Participation in Policymaking. Springer.

McGonigal, J. (2011). Reality is broken: Why games make us better and how they can change the world. New York: The Penguin Press.

McIver, D., Lengnick-Hall, C. a., Lengnick-Hall, M. L., \& Ramachandran, I. (2013). Understanding Work and Knowledge Management from a Knowledge-in-Practice Perspective. Academy of Management Review, 38(4), 597-620. https://doi.org/10.5465/amr.2011.0266

Miller, K. ., Wolf, M. J., \& Grodzinsky, F. S. (2017). Why We Should Have Seen That Coming. ORBIT Journal, 1(2), 54-64. https://doi.org/10.29297/orbit.v1i2.49

Mintzberg, H. (1998). Covert leadership: notes on managing professionals. Knowledge workers respond to inspiration, not supervision. Harvard Business Review, 76(6), 140-147.

Mizuyama, H., Yamaguchi, S., \& Sato, M. (2019). A Prediction Market-Based Gamified Approach to Enhance Knowledge Sharing in Organizations. Simulation and Gaming, 
50(5), 572-597. https://doi.org/10.1177/1046878119867382

Montola, M., Nummenmaa, T., Lucero, A., Boberg, M., \& Korhonen, H. (2009). Applying game achievement systems to enhance user experience in a photo sharing service. In 13th International MindTrek Conference: Everyday Life in the Ubiquitous Era (Vol. 4, pp. 9497). https://doi.org/10.1145/1621841.1621859

Morschheuser, B., \& Hamari, J. (2018). The Gamification of Work: Lessons From Crowdsourcing. Journal of Management Inquiry, 105649261879092. https://doi.org/10.1177/1056492618790921

Morschheuser, B., Hamari, J., Koivisto, J., \& Maedche, A. (2017). Gamified crowdsourcing: Conceptualization, literature review, and future agenda. International Journal of Human Computer Studies, 106, 26-43. https://doi.org/10.1016/j.ijhcs.2017.04.005

Morschheuser, B., Henzi, C., \& Alt, R. (2015). Increasing intranet usage through gamification - insights from an experiment in the banking industry. 48th Hawaii International Conference on System Sciences, (JANUARY), 635-642. https://doi.org/10.1109/HICSS.2015.83

Munday, P. (2017). Duolingo. Gamified learning through translation. Journal of Spanish Language Teaching, 4(2), 194-198. https://doi.org/10.1080/23247797.2017.1396071

Nelson, M. J. (2012). Soviet and American precursors to the gamification of work. In 16th International Academic MindTrek Conference on - MindTrek '12 (pp. 1-4). https://doi.org/10.1145/2393132.2393138

Nicholson, S. (2012). A User-Centered Theoretical Framework for Meaningful Gamification. In Games+Learning +Society 8.0 (pp. 1-7). Madison, WI. https://doi.org/10.1145/1979742.1979575

Osawa, H., Ema, A., Hattori, H., Akiya, N., Kanzaki, N., Kubo, A., ... Ichise, R. (2017). What is real risk and benefit on work with robots?: From the analysis of a robot hotel. In ACM/IEEE International Conference on Human-Robot Interaction (pp. 241-242). https://doi.org/10.1145/3029798.3038312

Oshri, I., Pan, S. L., \& Newell, S. (2006). Managing Trade-offs and Tensions between Knowledge Management Initiatives and Expertise Development Practices. Management Learning, 37(1), 63-82. https://doi.org/10.1177/1350507606060982

Palomo-Duarte, M., Dodero, J. M., \& García-Domínguez, A. (2014). Betting system for formative code review in educational competitions. Expert Systems with Applications, 41(5), 2222-2230. https://doi.org/10.1016/j.eswa.2013.09.020

Pedro, L., Santos, C., Aresta, M., \& Almeida, S. (2015). Peer-supported badge attribution in a collaborative learning platform: The SAPO Campus case. Computers in Human Behavior, 51, 562-567. https://doi.org/10.1016/j.chb.2015.03.024

Petelczyc, C. A., Capezio, A., Wang, L., Restubog, S. L. D., \& Aquino, K. (2018). Play at Work: An Integrative Review and Agenda for Future Research. Journal of Management, 44(1), 161-190. https://doi.org/10.1177/0149206317731519

Pratt, M. G. (2008). Fitting Oval Pegs into Round Holes - Tensions in Evaluating and Publishing Qualitative Research in Top-Tier North American Journals. Organizational Research Methods, 11(3), 481-509. https://doi.org/10.1177/1094428107303349

Pyöriä, P. (2005). The concept of knowledge work revisited. Journal of Knowledge Management, 9(3), 116-127. https://doi.org/10.1108/13673270510602818

Pyrko, I., Dörfler, V., \& Eden, C. (2017). Thinking together: What makes Communities of Practice work? Human Relations, 70(4), 389-409. https://doi.org/10.1177/0018726716661040

Rapp, A. (2017). From Games to Gamification: A Classification of Rewards in World of Warcraft for the Design of Gamified Systems. Simulation and Gaming, 48(3), 381-401. https://doi.org/10.1177/1046878117697147 
Rawlinson, G., Rawlinson, H. C., \& Willkinson, J. G. (1880). The History of Herodotus: A New English Version (D. Appleto, Vol. 4). New York: D. Appleton.

Reed, M. I. (1996). Expert Power and Control in Late Modernity: An Empirical Review and Theoretical Synthesis. Organization Studies, 17(4), 573-597. https://doi.org/10.1177/017084069601700402

Reich, R. B. (1991). The Work of nations : Preparing ourselves for 21st century capitalism. London Simon \& Schuster.

Reinhardt, W., Schmidt, B., Sloep, P., \& Drachsler, H. (2011). Knowledge Worker Roles and Actions - Results of Two Empirical Studies. Knowledge and Process Management, 18(3), 150-174. https://doi.org/10.1002/kpm

Rey, P. (2014). Gamification and post-Fordist capitalism. In S. P. Walz \& S. Deterding (Eds.), The Gameful World. Approaches, Issues, Applications (pp. 277-295). Boston, MA: MIT Press.

Rimon, G. (2015). Gamification is More than a Productivity Tool. It Tunes Organizational Change. Retrieved September 18, 2015, from http://www.gameffective.com/customerservice/gamification-more-than-a-productivity-tool/

Rinc, S. (2014). Integrating Gamification with Knowledge Management. In Management, Knowledge and Learning, International Conference (pp. 997-1003). Portoroz.

Robinson, O. C. (2014). Sampling in Interview-Based Qualitative Research: A Theoretical and Practical Guide. Qualitative Research in Psychology, 11(1), 25-41. https://doi.org/10.1080/14780887.2013.801543

Robson, K., Plangger, K., Kietzmann, J. H., McCarthy, I., \& Pitt, L. (2016). Game on: Engaging customers and employees through gamification. Business Horizons, 59(1), 29-36. https://doi.org/10.1016/j.bushor.2015.08.002

Ryan, R. M., \& Deci, E. L. (2000). Self-determination theory and the facilitatiton of intrinsic motivation, social development, and well-being. American Psychological Association, 55(1), 68-78.

Santoro, M., Borges, M. R. S., \& Rezende, E. A. (2006). Collaboration and knowledge sharing in network organizations. Expert Systems with Applications, 31, 715-727. https://doi.org/10.1016/j.eswa.2006.01.002

Saunders, M. N. K., Lewis, P., \& Thornhill, A. (2019). Research Methods for Business Students. London: Pearson Education, Limited.

Saunders, M. N. K., \& Townsend, K. (2016). Reporting and Justifying the Number of Interview Participants in Organization and Workplace Research. British Journal of Management, 27(4), 836-852. https://doi.org/10.1111/1467-8551.12182

Scarbrough, H. (1999). Knowledge as work: Conflicts in the management of knowledge workers. Technology Analysis and Strategic Management, 11(1), 5-16. https://doi.org/10.1080/095373299107546

Scheiner, C. W. (2015). The Motivational Fabric of Gamified Idea Competitions: The Evaluation of Game Mechanics from a Longitudinal Perspective. Creativity and Innovation Management, 24(2), 341-352.

Shpakova, A., Dörfler, V., \& MacBryde, J. (2017). Changing the Game: A Case for Gamifying Knowledge Management. World Journal of Science, Technology and Sustainable Development, 14(2/3), 143-154. https://doi.org/10.1108/WJSTSD-01-2017-0002

Shpakova, A., Dörfler, V., \& MacBryde, J. (2019). Gamifying the process of innovating. Innovation: Organization \& Management. https://doi.org/10.1080/14479338.2019.1642763

Spanellis, A. (2020). AI \& Gamification in Knowledge Management: Issues of Identity in Communities of Practice. In Presentation at the Artificial Intelligence Initiative. Liverpool, UK: Risk Institute, University of Liverpool. Retrieved from 
https://riskinstitute.uk/events/aiinitiative/

Stierand, M. B. (2015). Developing creativity in practice: Explorations with world- renowned chefs. Management Learning, 46(5), 598-617. https://doi.org/10.1177/1350507614560302

Vassileva, J. (2012). Motivating participation in social computing applications: a user modeling perspective. User Modeling and User-Adapted Interaction, 22(1-2), 177-201. https://doi.org/10.1007/s11257-011-9109-5

Wang, Z., \& Wang, N. (2012). Knowledge sharing, innovation and firm performance. Expert Systems with Applications, 39(10), 8899-8908. https://doi.org/10.1016/j.eswa.2012.02.017

Warmelink, H., Koivisto, J., Mayer, I., Vesa, M., \& Hamari, J. (2020). Gamification of production and logistics operations: Status quo and future directions. Journal of Business Research, 106(September 2018), 331-340. https://doi.org/10.1016/j.jbusres.2018.09.011

Werbach, K., \& Hunter, D. (2012). For the win: How game thinking can revolutionize your business. Philadelphia, PA: Wharton Digital Press.

Wiig, K. M. (1997). Knowledge management: Where did it come from and where will it go? Expert Systems with Applications, 13(1), 1-14. https://doi.org/10.1016/S09574174(97)00018-3

Williams, D., Consalvo, M., Caplan, S., \& Yee, N. (2009). Looking for gender: Gender roles and behaviors among online gamers. Journal of Communication, 59(4), 700-725. https://doi.org/10.1111/j.1460-2466.2009.01453.x

Xu, F., Buhalis, D., \& Weber, J. (2017). Serious games and the gamification of tourism. Tourism Management, 60, 244-256. https://doi.org/10.1016/j.tourman.2016.11.020

Zicherman, G., \& Cunningham, C. (2011). Gamification by design. Sebastobol, CA: O'Reilly Media.

Zimmerling, E., Hoflinger, P. J., Sandner, P., \& Welpe, I. M. (2016). Increasing the Creative Output at the Front End of Innovation - A Concept for a Gamified Internal Enterprise Ideation Platform. In Proceedings of the 49th Annual Hawaii International Conference on System Sciences (pp. 837-846). Koloa, HI, USA.

Zuckerman, O., \& Gal-Oz, A. (2014). Deconstructing gamification: evaluating the effectiveness of continuous measurement, virtual rewards, and social comparison for promoting physical activity. Personal and Ubiquitous Computing, 18(7), 1705-1719. https://doi.org/10.1007/s00779-014-0783-2 
8 Point-by-point response to reviewers 